\title{
HAEMOLYSIN AND ENZYME PATTERNS OF COAGULASE- POSITIVE STAPHYLOCOCCI ISOLATED FROM TOXIC EPIDERMAL NECROLYSIS, RITTER'S DISEASE AND IMPETIGO CONTAGIOSA
}

\author{
J. P. Arbuthnott*, C. G. Gemmell $\dagger$, Janet Kent $\ddagger$ and A. Lyell \\ Department of Microbiology, The University, Glasgow, and \\ Department of Dermatology, The Royal Infirmary, Glasgow
}

THE recent outbreak of staphylococcal toxic epidermal necrolysis (TEN; "Ritter's type" of TEN) in the Glasgow area, described by Lyell, Dick and Alexander (1969), prompted us to consider whether strains of Staphylococcus aureus isolated from TEN differ in any obvious way from strains isolated from impetigo. The histology of Ritter's type of TEN, in particular the absence of polymorphonuclear leucocytic reaction and of stainable organisms, suggested that the extensive splitting of the epidermis, which resembles the effect of scalding, might be due to a diffusible product of the staphylococcus rather than local massive proliferation of the organism. It therefore seemed of interest to investigate the patterns of toxins and enzymes produced by isolates from TEN and impetigo. At the outset it was realised that probably no single product of the staphylococcus is responsible for this particular manifestation of disease. Equally the possibility that factors specific to individual hosts may play a significant role in TEN must be acknowledged, although these have not been investigated in this study which is concerned only with the properties of the staphylococci isolated.

Previous studies of staphylococci from skin infections have emphasised the association of phage-type 71 staphylococci with impetigo contagiosa (Parker, Tomlinson and Williams, 1955; Spittlehouse, 1955) and more recently with TEN (Holzel and Jacobs, 1966; Tyson, Ushinski and Kisilevsky, 1966; Jefferson, 1967; Lowney et al., 1967; Lyell, 1967; Samuels, 1967). Tomlinson and Parker (1956) described the ability of type-71 strains of $S$. aureus from skin infections to cause opacity on serum agar. Subsequently Parker (1958) emphasised the correlation between a positive serum opacity reaction, a negative egg-yolk reaction and the ability to give a sharply delimited zone of inhibition of Corynebacterium diphtheriae among type-71 staphylococci isolated from superficial skin lesions, mainly impetigo.

To our knowledge, no attempt has been made to compare the enzyme or toxin patterns of strains isolated from TEN and impetigo. It was therefore

Received 5 Mar. 1969; accepted 3 May 1969.

* Alan Johnston, Lawrence and Moseley Research Fellow of The Royal Society.

$\dagger$ Nuffield Foundation Research Fellow.

$\ddagger$ Completed part of this work while holding a Carnegie Vacation Scholarship.

J. MED. MICROBIOL.-VOL. 2 (1969) 
decided to screen a number of strains from both types of lesion for fibrinolysin, gelatinase, egg-yolk factor, lipase and hyaluronidase. In addition the production of haemolytic toxins was assessed both quantitatively and qualitatively. The investigation covers the period October 1967 to October 1968 and includes isolates from hospitals in Glasgow as well as from other parts of the British Isles.

\section{Materials AND METHODS}

Isolates. These consisted of 26 coagulase-positive staphylococci isolated in Glasgow and other parts of Great Britain from cases of toxic epidermal necrolysis (TEN), Ritter's disease (exfoliative dermatitis of the newborn) and impetigo contagiosa.

Phage typing of each isolate was carried out at the Staphylococcus Reference Laboratory, Central Public Health Laboratory, Colindale.

\section{Haemolytic activity of isolates}

Haemolysis on blood agar. Each isolate was grown on Oxoid Blood Agar Base No. 2 medium containing 10 per cent. $(\mathrm{v} / \mathrm{v})$ of saline-washed suspensions of either sheep, rabbit or human red blood cells (RBC) and examined for the production of zones of haemolysis around the colonies after overnight incubation at $37^{\circ} \mathrm{C}$. The haemolysin patterns on blood agar were determined by streaking each isolate on similar blood agar plates and placing sterile filter-paper strips soaked in commercial staphylococcus $\alpha$-antitoxin (Batch No. CPP76/63, Wellcome Research Laboratories, Beckenham, England) at right-angles to the streaks in a manner similar to that described by Elek and Levy $(1950,1954)$. The plates were incubated at $37^{\circ} \mathrm{C}$ for $24 \mathrm{hr}$ and examined for patterns of neutralisation of haemolysis.

Preparation of culture supernates. Crude culture supernates were prepared by freezing and thawing 48-hr cultures of the isolates grown on semi-solid nutrient agar in an atmosphere of 20 per cent. $\mathrm{CO}_{2}$ at $37^{\circ} \mathrm{C}$ as previously described by Lominski and Arbuthnott (1962).

Assay of haemolytic activities of supernates. The haemolytic activities of culture supernates were determined by the method of Lominski and Arbuthnott with 2 per cent. (v/v) suspensions of either rabbit, sheep, human or horse RBC as indicator. The titre was taken as the dilution that caused 50 per cent. haemolysis of the suspension after 60 minutes' incubation at $37^{\circ} \mathrm{C}$. The presence of $\beta$-haemolysin was detected by a further incubation of the titrations against sheep $\mathrm{RBC}$ at $4^{\circ} \mathrm{C}$.

Neutralisability by $\alpha$-antitoxin. Neutralisation of $\alpha$-haemolysin was carried out as follows. The dilution of commercial $\alpha$-antitoxin that neutralised 8 minimum hae molytic doses (MHD) of freshly prepared Wood $46 \alpha$-haemolysin was determined. Then each culture supernate was diluted to contain $8 \mathrm{MHD}$ per $0.2 \mathrm{ml}$. This amount of haemolysin was thereafter allowed to interact with the above-mentioned dilution of a standard antiserum $(0.5 \mathrm{ml})$ for $90 \mathrm{~min}$. at $37^{\circ} \mathrm{C} ; 0.3 \mathrm{ml}$ of a 3 per cent. suspension of saline-washed rabbit $\mathrm{RBC}$ was then added to each tube and the incubation continued for a further $60 \mathrm{~min}$. In this way each supernate was screened for the presence of non-neutralisable haemolysin. This procedure was repeated with a dilution of culture supernate containing $100 \mathrm{MHD}$ per $0.2 \mathrm{ml}$ and the appropriate dilution of standard antitoxin that neutralised $100 \mathrm{MHD}$ of $\alpha$-haemolysin from strain Wood 46. Where the haemolysin titre was less than that necessary to give $100 \mathrm{MHD}$ per $0.2 \mathrm{ml}$, as in the case of weak haemolysin-producing strains, $0.2 \mathrm{ml}$ of undiluted culture supernate was used in the test. In order to minimise error, the Wood $46 \alpha$-haemolysin preparation and the standard antiserum were checked before each series of tests.

Inhibition of non-neutralisable haemolysin by normal horse-serum. To test the inhibitory effect of normal serum on the non-neutralisable haemolysin, $0 \cdot 25-\mathrm{ml}$ amounts of normal horse serum (containing no detectable $\alpha$-antitoxin) were added to each tube in a series of doubling dilutions of supernate in $0.5 \mathrm{ml}$ diluent. After incubation for $90 \mathrm{~min}$. at $37^{\circ} \mathrm{C}$, $0.25 \mathrm{ml}$ of a 3 per cent. suspension of rabbit RBC was added and the tubes were re-incubated at $37^{\circ} \mathrm{C}$ and the titre was recorded at $60 \mathrm{~min}$. 
Thermostability of non-neutralisable haemolysin. Haemolysin preparations from strains that produced non-neutralisable haemolysin were heated at $60^{\circ} \mathrm{C}$ for various times and the rabbit lysin titre was determined after each time of heating.

\section{Tests for other properties of the isolates}

Coagulase production was estimated by the addition of 5 drops of an overnight broth culture of the organism to $0.5 \mathrm{ml}$ of a 1 in 10 dilution of human plasma in saline according to the method of Gillespie (1943). All isolates were coagulase-positive.

The production of gelatinase was demonstrated by streaking each isolate on nutrient agar containing 10 per cent. gelatin and incubating the plates for 3 days at $37^{\circ} \mathrm{C}$. Gelatin hydrolysis was detected by flooding the plates with an acid solution of mercuric chloride.

The ability to hydrolyse tributyrin was shown by streaking each isolate on to nutrient agar containing 1 per cent. tributyrin (British Drug Houses Ltd) and examining the plates for clearing around the streak after 24 hours' incubation at $37^{\circ} \mathrm{C}$. A + reaction was recorded if the zone of clearing was between 0 and $3 \mathrm{~mm}$ wide and a ++ reaction was recorded if the zone was greater than $3 \mathrm{~mm}$ wide.

Fibrinolysin activity was detected by streaking each isolate on to nutrient agar containing 1 per cent. fresh human plasma heated at $56^{\circ} \mathrm{C}$ for $30 \mathrm{~min}$. Clearing around the streaks indicated breakdown of fibrinogen.

Hyaluronidase was estimated by a modification of the turbidity reduction assay method described by Dorfmann (1955). Staphylococcal hyaluronidase was prepared by growing each isolate in nutrient broth containing 1 per cent. glucose with constant agitation at $37^{\circ} \mathrm{C}$ for $7 \mathrm{hr}$. After centrifugation, the supernate was tested for enzyme content by comparing its activity with that of a commercial preparation of hyaluronidase $e x$ bovine testes (KochLight Ltd) against hyaluronic acid ex human umbilical cord (Koch-Light Ltd) as substrate. Values of hyaluronidase activity were expressed as International Units (IU).

Production of egg-yolk factor. Each isolate was tested for the production of egg-yolk factor by growing the strain for 7 days at $37^{\circ} \mathrm{C}$ in nutrient broth containing 5 per cent. concentrated egg-yolk emulsion (Oxoid Ltd). The appearance of dense opacity was recorded as a positive result.

Dermonecrotic activity. The ability of each supernate to cause dermonecrosis in mouse skin was tested by injecting small volumes $(0.1 \mathrm{ml})$ subcutaneously into the skin of the shaven abdomen of Porton white mice of $20-25 \mathrm{~g}$.

\section{RESUlTS AND DISCUSSION}

In considering the results the strains of staphylococci investigated have been divided, for the purpose of comparison, into two groups according to clinical diagnoses of the cases from which they were isolated. Group L (for localised disease) contained staphylococci from the lesions of patients with unequivocal impetigo contagiosa. Group E (for extensive disease) contained strains isolated from TEN and Ritter's disease and from those cases of extensive impetigo in which these diagnoses were seriously considered.

\section{Phage typing}

The results of phage typing (table 1) are in general agreement with those of previous workers: 24 of the 26 isolates tested belonged to phage-group II; the remaining 2 isolates (no. 5 and 16) showed mixed group-I and group-III characteristics. Of the 24 group-II isolates, 23 were lysed by phage 71 alone or by phage 71 and phage 55 ; isolate no. 24 was lysed by phages $3 \mathrm{~A}, 3 \mathrm{C}, 55$ and 71. Parker and Simmons (1959) noted that isolates developed susceptibility 
to lysis by phage 55 after storage for several months. Our isolates were phage typed after storage at $4^{\circ} \mathrm{C}$ and this probably explains the large number showing susceptibility to phage 55 .

\section{TABLE I}

(a) Phage-types and enzyme patterns of isolates from cases of extensive disease (Group E)

\begin{tabular}{|c|c|c|c|c|c|c|}
\hline $\begin{array}{c}\text { Isolate } \\
\text { no. }\end{array}$ & Phage-type & Gelatinase & Fibrinolysin & $\begin{array}{l}\text { Egg-yolk } \\
\text { factor }\end{array}$ & $\begin{array}{c}\text { Lipase } \\
\text { (tributyrinase) }\end{array}$ & $\begin{array}{c}\text { Hyaluronidase } \\
\text { (IU) }\end{array}$ \\
\hline $\begin{array}{r}1 \\
2 \\
3 \\
4 \\
5 \\
6 \\
7 \\
8 \\
9 \\
10 \\
11 \\
12 \\
13 \\
14 \\
15\end{array}$ & $\begin{array}{r}55 w^{*} / 71 \\
55 \mathrm{w} / 71 \\
55 / 71 \\
55 \mathrm{w} / 71 \\
29 / 75 \\
55 / 71 \\
71 \\
55 / 71 \\
55 / 71 \\
55 / 71 \\
55 / 71 \\
71 \\
71 \\
71 \\
71\end{array}$ & $\begin{array}{l}+ \\
+ \\
+ \\
+ \\
+ \\
+ \\
+ \\
+ \\
+ \\
+ \\
+ \\
+ \\
+ \\
+ \\
+\end{array}$ & $\begin{array}{l} \pm \\
- \\
= \\
\overline{+} \\
\pm \\
+ \\
+ \\
+ \\
+ \\
+ \\
+ \\
+\end{array}$ & $\begin{array}{l}- \\
= \\
= \\
- \\
= \\
\overline{+} \\
= \\
= \\
\overline{-} \\
\pm \\
-\end{array}$ & $\begin{array}{l}++ \\
++ \\
+ \\
+ \\
+ \\
++ \\
+ \\
++ \\
+ \\
+ \\
+ \\
+ \\
+ \\
+\end{array}$ & $\begin{array}{c}10 \cdot 3 \\
9 \cdot 0 \\
26 \cdot 7 \\
17 \cdot 6 \\
\text { nd } \dagger \\
22 \cdot 8 \\
6 \cdot 3 \\
12 \cdot 8 \\
21 \cdot 2 \\
19 \cdot 8 \\
21 \cdot 6 \\
16 \cdot 2 \\
25 \cdot 0 \\
15 \cdot 1 \\
17 \cdot 4\end{array}$ \\
\hline
\end{tabular}

(b) Phage-types and enzyme patterns of isolates from cases of localised disease (Group L)

\begin{tabular}{c|c|c|c|c|c|c}
\hline $\begin{array}{c}\text { Isolate } \\
\text { no. }\end{array}$ & Phage-type & Gelatinase & Fibrinolysin & $\begin{array}{c}\text { Egg-yolk } \\
\text { factor }\end{array}$ & $\begin{array}{c}\text { Lipase } \\
\text { (tributyrinase) }\end{array}$ & $\begin{array}{c}\text { Hyaluronidase } \\
\text { (IU) }\end{array}$ \\
\hline 16 & $\begin{array}{c}29 / 52 / 52 \mathrm{~A} / 79 / 80 \\
6 \mathrm{w} / 42 \mathrm{E} / 47 \mathrm{w} / 54 \mathrm{w}\end{array}$ & + & + & - & - & $17 \cdot 2$ \\
& $83 \mathrm{~A} / 85 \mathrm{w} / 55 / 71$ & + & + & - & ++ & \\
17 & $55 / 71$ & + & + & - & ++ & $22 \cdot 2$ \\
18 & 71 & + & + & - & - & $6 \cdot 3$ \\
19 & $55 / 71$ & + & + & + & + & $2 \cdot 7$ \\
20 & $55 / 71$ & + & + & + & + & $21 \cdot 6$ \\
21 & 71 & + & - & - & + & $12 \cdot 1$ \\
22 & $55 \mathrm{w} / 71$ & + & + & - & + & $15 \cdot 5$ \\
24 & $3 \mathrm{~A} / 3 \mathrm{C} / 55 / 71$ & + & + & - & + & $16 \cdot 2$ \\
25 & $55 / 71$ & + & - & - & + & $15 \cdot 0$ \\
26 & $55 / 71$ & + & - & - & + & $28 \cdot 8$ \\
\hline
\end{tabular}

* w denotes a weak reaction. $\quad+\mathrm{nd}=$ Not determined.

\section{Enzyme patterns}

These results are also given in table I. The pattern of proteolytic activity is typical of coagulase-positive staphylococci of human origin (Elek, 1959). All isolates hydrolysed gelatin and 15 of 26 exhibited fibrinolysin activity. The low incidence of a positive egg-yolk reaction ( 4 of 26) agrees with the observation of Parker (1958) that very few phage-type 71 isolates from superficial skin lesions had positive egg-yolk reactions. By contrast, most of the isolates 
(21 of 26) hydrolysed tributyrin and the pattern, egg yolk - /lipase + , was found in 18 of the isolates.

Elek (1959) and Saggers and Stewart (1968) reported that 99-100 per cent. of staphylococci of human origin possessed lipolytic activity. The 81 per cent. incidence of lipase activity observed in the present survey is therefore lower than expected. It would be desirable to carry out a more extensive investigation of lipase production among staphylococci isolated from superficial skin infections, especially since Saggers and Stewart have suggested that the possession of a flexible lipase mechanism might account for the persistence of staphylococci in the fatty secretions of the skin.

The quantitative estimation of hyaluronidase activity revealed a wide range of activity among the isolates and no obvious differences between the two groups. In group E, values ranged from $6 \cdot 3$ to $26.7 \mathrm{IU}$ per ml (average $=17 \cdot 2$ ), and the values for group L from $6 \cdot 3$ to $28 \cdot 8 \mathrm{IU}$ per ml (average $=17 \cdot 0$ ).

There is thus no evidence from in-vitro estimates of hyaluronidase activity to indicate that staphylococci isolated from extensive skin lesions are any better endowed with the potential to "spread" than are staphylococci isolated from more localised ones. Extrapolation from in-vitro to in-vivo situations is difficult, but the present findings seem to agree with the generally held view that hyaluronidase production cannot be correlated with the invasiveness of individual strains.

\section{Haemolysin patterns}

The first TEN isolate to be examined produced marked zones of sharply delimited haemolysis on human and horse blood agar, and when cultured on semi-solid nutrient agar under 20 per cent. $\mathrm{CO}_{2}$ reproducibly yielded low-titre, thermostable haemolysin that was not neutralised by $\alpha$-antitoxin. In view of the relative rarity of strains of this type, a survey of the haemolysin patterns was undertaken. Basically three tests were carried out with each isolate. (1) The haemolytic activities of crude culture supernates against rabbit, sheep, human and horse erythrocytes were determined. (2) A tube test to determine whether this haemolytic activity was neutralised by $\alpha$-antitoxin was carried out. (3) Patterns of neutralisation obtained by the method of Elek and Levy (1950) with $\alpha$-antitoxin on rabbit, sheep and human blood agar were recorded.

The results of these tests are shown in table II. Within group E, two isolates (no. 7 and 11) had titres of 20 MHD per $\mathrm{ml}$ or less against rabbit RBC, 5 isolates had titres of between 20 and 160 MHD per $\mathrm{ml}$, and the remainder (8 isolates) had titres of $320 \mathrm{MHD}$ per $\mathrm{ml}$ or greater; the average titre against rabbit erythrocytes within this group was 355 MHD per ml. By contrast in group $\mathrm{L}$, one isolate produced no detectable haemolysin, one isolate had a titre of $160 \mathrm{MHD}$ per $\mathrm{ml}$ and the remainder had titres of $320 \mathrm{MHD}$ per $\mathrm{ml}$ or greater; the average titre against rabbit erythrocytes in this group was 1008 MHD per $\mathrm{ml}$. Thus the proportion of isolates having a low rabbit lysin titre was considerably greater in group $\mathrm{E}$.

All isolates having titres of $20 \mathrm{MHD}$ per $\mathrm{ml}$ or greater were now subjected to test 2. The haemolytic activity of supernatants of cultures from the 14 
isolates from group $\mathrm{E}$ was so tested; in 8 it was not neutralised by the amount of $\alpha$-antitoxin that neutralised $8 \mathrm{MHD}$ of $\alpha$-toxin, and in all but one it was not

TABLE II

(a) Haemolysin patterns and results of neutralisation tests in Group E

\begin{tabular}{|c|c|c|c|c|c|c|c|c|c|}
\hline \multirow{2}{*}{$\begin{array}{l}\text { Isolate } \\
\text { no.** }\end{array}$} & \multicolumn{4}{|c|}{$\begin{array}{l}\text { Minimal haemolytic doses (MHD) } \\
\text { per ml culture supernate against } \\
\text { RBC of }\end{array}$} & \multicolumn{2}{|c|}{$\begin{array}{c}\text { Result of tube } \\
\text { neutralisation test } \\
\text { with } \alpha \text {-antitoxin } \uparrow \text { at }\end{array}$} & \multicolumn{3}{|c|}{$\begin{array}{c}\text { Haemolysin detected in plate } \\
\text { neutralisation tests with stated } \\
\text { RBC }\end{array}$} \\
\hline & rabbit & sheep & $\operatorname{man}$ & horse & $8 \mathrm{MHD}$ & $100 \mathrm{MHD}$ & rabbit & sheep & human \\
\hline $\begin{array}{r}1 \\
2 \\
3 \\
4 \\
5 \\
6 \\
7 \\
8 \\
9 \\
10 \\
11 \\
12 \\
13 \\
14 \\
15\end{array}$ & $\begin{array}{r}80 \\
320 \\
1280 \\
640 \\
1280 \\
80 \\
16 \\
640 \\
80 \\
160 \\
20 \\
320 \\
320 \\
80 \\
320\end{array}$ & $\begin{array}{r}20 \\
10 \\
20 \\
40 \\
40 \\
20 \\
<2 \\
160 \\
20 \\
20 \\
<20 \\
40 \\
40 \\
20 \\
160\end{array}$ & $\begin{array}{l}20 \\
20 \\
40 \\
40 \\
40 \\
40 \\
<2 \\
40 \\
40 \\
40 \\
20 \\
40 \\
40 \\
40 \\
80\end{array}$ & $\begin{array}{r}<10 \\
<20 \\
\text { nd } \ddagger \\
\text { nd } \\
\text { nd } \\
20 \\
<2 \\
20 \\
10 \\
<10 \\
<2 \\
20 \\
20 \\
20 \\
<20\end{array}$ & $\begin{array}{r}\mathbf{N N} \\
\mathbf{N} \\
\mathbf{N} \\
\mathbf{N} \\
\mathbf{N} \\
\mathbf{N} \\
\mathbf{n d} \\
\mathbf{N} \\
\mathbf{N} \\
\mathbf{N N} \\
\mathbf{N N} \\
\mathbf{N N} \\
\mathbf{N} \\
\mathbf{N} \\
\mathbf{N N}\end{array}$ & $\begin{array}{r}\text { NN } \\
\text { NN } \\
\text { NN } \\
\text { NN } \\
\text { N } \\
\text { NN } \\
\text { nd } \\
\text { NN } \\
\text { NN } \\
\text { NN } \\
\text { NN } \\
\text { NN } \\
\text { NN } \\
\text { NN } \\
\text { NN }\end{array}$ & $\begin{array}{c}\alpha \\
\alpha \\
\alpha, \delta \\
\alpha, \delta \\
\alpha, \delta \\
\alpha, \delta \\
\alpha \\
\alpha \\
\alpha, \delta \\
\alpha, \delta \\
\alpha, \delta \\
\alpha, \delta \\
\alpha, \delta \\
\alpha \\
\alpha, \delta\end{array}$ & $\begin{array}{c}\delta \\
\alpha, \delta \\
\alpha, \delta \\
\alpha, \delta \\
\alpha, \delta \\
\delta \\
\text { NH§ } \\
\alpha \\
\delta \\
\alpha \\
\delta \\
\alpha, \delta \\
\alpha, \delta \\
\text { NH } \\
\alpha, \beta, \delta\end{array}$ & $\begin{array}{c}\delta \\
\delta \\
\delta \\
\delta \\
\delta \\
\delta \\
\mathrm{NH} \\
\delta \\
\delta \\
\delta \\
\delta \\
\delta \\
\delta \\
\delta \\
\delta\end{array}$ \\
\hline
\end{tabular}

(b) Haemolysin patterns and results of neutralisation tests in Group $L$

\begin{tabular}{l|r|r|r|r|r|r|r|r|c}
\hline 16 & 2560 & 160 & 40 & 20 & $\mathbf{N}$ & $\mathbf{N}$ & $\alpha, \delta$ & $\alpha, \delta$ & $\delta$ \\
17 & 640 & 80 & 40 & $<20$ & $\mathbf{N}$ & $\mathbf{N N}$ & $\alpha$ & $\delta$ & $\delta$ \\
18 & 640 & 80 & 40 & $<20$ & $\mathbf{N}$ & $\mathbf{N N}$ & $\alpha, \delta$ & $\alpha, \delta$ & $\delta$ \\
19 & $<2$ & 2 & $<2$ & $<2$ & $\mathbf{n d}$ & $\mathbf{n d}$ & $\mathbf{N H}$ & $\mathbf{N H}$ & $\mathbf{N H}$ \\
20 & 1280 & 80 & 40 & 20 & $\mathbf{N}$ & $\mathbf{N N}$ & $\alpha$ & $\alpha$ & $\alpha, \delta$ \\
21 & 1280 & 160 & 40 & 20 & $\mathbf{N}$ & $\mathbf{N N}$ & $\alpha, \delta$ & $\alpha, \beta, \delta$ & $\delta$ \\
22 & 640 & $640 / 5000$ & 80 & $<20$ & $\mathbf{N}$ & $\mathbf{N N}$ & $\alpha, \delta$ & $\alpha, \beta$ & $\delta$ \\
23 & 1280 & 320 & 160 & 20 & $\mathbf{N}$ & $\mathbf{N N}$ & $\alpha, \delta$ & $\alpha$ & $\delta$ \\
24 & 160 & 20 & 40 & $<10$ & $\mathbf{N N}$ & $\mathbf{N N}$ & $\alpha, \delta$ & $\delta$ & $\delta$ \\
25 & 320 & 20 & 20 & nd & $\mathbf{N}$ & $\mathbf{N N}$ & $\alpha$ & $\alpha, \delta$ & $\delta$ \\
26 & 1280 & 20 & 40 & nd & $\mathbf{N}$ & $\mathbf{N N}$ & $\alpha, \delta$ & $\alpha, \delta$ & $\delta$ \\
\hline
\end{tabular}

* No. 1-5 denote isolates from cases 1-5 described in the paper by Lyell et al. (1969). $\dagger \mathrm{N}$ denotes neutralisation by $\alpha$-antitoxin in amounts capable of neutralising 8 or 100 MHD of $\alpha$-toxin; NN denotes not neutralised. $\ddagger$ nd $=$ Not determined. $\S \mathrm{NH}=$ No haemolysis. $\|=$ Titre of hot-cold haemolysin against sheep $\mathrm{RBC}$.

neutralised by the amount that neutralised 100 MHD of $\alpha$-toxin. On the other hand, within group L, only one of the 10 supernatants submitted to test 2 was not neutralised by the amount of antitoxin that neutralised 8 MHD of $\alpha$-toxin; again all but one were not neutralised by the amount that neutralised 100 MHD of $\alpha$-toxin. These results indicated that there was no strict correlation between haemolysin pattern and clinical source, but that group E contained 
an unexpectedly high number of isolates predominantly producing a low-titre haemolysin that was not $\alpha$-haemolysin.

The question of the identity of this haemolysin now arose. It seems most likely that it is identical with $\delta$-haemolysin. In view of the considerable controversy as to the exact nature of $\delta$-haemolysin (Bernheimer, 1969), considerable caution must be exercised in making this assertion; nevertheless

TABLE III

Characteristics of the non-neutralisable haemolysin

(a) Inhibition by normal horse serum

\begin{tabular}{c|c|c}
\hline Isolate no. & $\begin{array}{c}\text { Titre against rabbit RBC } \\
\text { in absence of normal horse } \\
\text { serum }\end{array}$ & $\begin{array}{c}\text { Titre against rabbit RBC } \\
\text { in presence of normal horse } \\
\text { serum }\end{array}$ \\
\hline 1 & 80 & $<4$ \\
6 & 80 & 4 \\
9 & 80 & 4 \\
10 & 80 & 4 \\
11 & 20 & 4 \\
\hline
\end{tabular}

(b) Thermostability of non-neutralisable haemolysin from isolate no. $9^{*}$

\begin{tabular}{c|c}
\hline Time of heating at $60^{\circ} \mathrm{C}$ (min.) & Titre against rabbit RBC \\
\hline 5 & 160 \\
10 & 320 \\
15 & 160 \\
30 & 320 \\
60 & 320 \\
\hline Control unheated & 320 \\
\hline
\end{tabular}

* For these experiments haemolysin was produced from isolate no. 9 grown on Cellophane sheets on nutrient agar.

five findings suggest this identity. (1) The crude haemolysin was inhibited by normal horse serum (table III). (2) The crude haemolysin was thermostable (table III). (3) The spectrum of haemolytic activity for rabbit, sheep, human and horse RBC closely resembled that for $\delta$-haemolysin (Gladstone, 1966). (4) Haemolysin production was enhanced by culturing the isolates on Cellophane sheets placed on nutrient agar. For instance, with isolate no. 9, the potency of haemolysin obtained from cultures on Cellophane was four times that obtained from cultures on semi-solid agar. (5) On purification, the haemolysin behaved similarly to that studied by Wiseman and Caird (1968).

These properties agree closely with previous descriptions of $\delta$-haemolysin by various workers (Gladstone; Hallander, 1968; Wiseman and Caird).

The haemolytic patterns obtained in the plate test of Elek and Levy (1950) with strain Wood 46 as a standard reference are also shown in table II. These 
indicate that, by this test, all isolates with the exception of no. 19 gave either $\alpha$ or $\alpha, \delta$ patterns on rabbit blood agar. On agar containing sheep RBC the $\alpha$-haemolysin pattern was less common and six isolates showed only the $\delta$ pattern, and three isolates the $\alpha, \beta, \delta$ pattern. (One of these, no. 22, was subsequently shown to produce high titres of $\beta$-haemolysin in the tube test.) On plates containing human $\mathrm{RBC}$, two isolates produced no haemolysis, one showed an $\alpha, \delta$ pattern and the remainder showed haemolysis attributable to $\delta$-toxin only. These observations agree with the findings of Elek and Levy (1954), who showed poor correlation between haemolysin patterns determined on blood agar and haemolytic titres of culture supernates. We feel that this emphasises the value of quantitative estimation of haemolytic titres against erythrocytes from different species.

Attempts to relate clinical symptoms of staphylococcal infections to the possession of individual toxic or potentially toxic extracellular products of this organism have in general proved unsuccessful. Indeed the validity of relating in-vitro characters to their role in vivo has been often justifiably criticised. In addition, individual variation in the host may well play a dominant part in the outcome of the interaction between the host and the staphylococcus. Nevertheless, in our view, the possibility cannot be excluded that a study of in-vitro characters may give a clue to the mechanism of certain types of staphylococcal infections. Indeed such an approach presents one of the few ways of tackling the problem.

In the present investigation no enzyme or haemolysin pattern was found to be entirely typical of group-E or group-L isolates. However, an unexpectedly high number of isolates in group $\mathrm{E}$ ( 8 of 15 ) produced predominantly a haemolysin that has been presumptively identified as $\delta$-toxin. Each of these eight isolates produced more $\delta$-toxin in vitro than all but one of the strains in group L. This finding raises the possibility that $\delta$-toxin may play a role in Ritter's type of TEN and extensive impetigo. On the other hand, six isolates in group E produced $\alpha$-toxin in excess of $\delta$-toxin and could not be distinguished from isolates in group L. Nevertheless it is felt that the role of $\delta$-toxin in superficial staphylococcal infections should be further investigated. The observation that small amounts (4 MHD) of $\delta$-toxin caused marked dermonecrosis within 6-10 hr after subcutaneous injection into mice reinforces this opinion.

The findings presented in this paper are consistent with the clinical difficulty experienced in distinguishing clearly between Ritter's type of TEN and impetigo in all cases.

\section{SUMMARY}

Strains of Staphylococcus aureus isolated from toxic epidermal necrolysis and Ritter's disease (named collectively "Ritter's type" of TEN) and from extensive cases of impetigo contagiosa, in which the diagnosis of Ritter's type of TEN was considered seriously, were assigned to group E (extensive lesions) and were compared with strains of $S$. aureus isolated from unequivocal impetigo contagiosa (group L-localised lesions); 24 of the 26 isolates examined belonged to phage-group II. 
Strains from groups $\mathrm{E}$ and $\mathrm{L}$ were generally similar in their patterns of proteolytic activity, low incidence of positive egg-yolk reaction, possession of lipase and production of hyaluronidase. The difference lay in the many isolates in group $\mathrm{E}$ that produced a low-titre lysin active against rabbit red cells that was not $\alpha$-haemolysin. The average titre of lysin active against rabbit erythrocytes in group E was 355 MHD per ml and in group L 1008 MHD per ml. Reasons are given for supposing that this low titre rabbit cell lysin is identical with staphylococcal $\delta$-toxin. It is suggested that $\delta$-toxin may play a part in the pathogenesis of Ritter's type of TEN and extensive impetigo.

The authors gratefully acknowledge the co-operation of Drs M. J. Samuels and E. G. Hall at the Alder Hey Children's Hospital, Liverpool, Dr K. V. Sanderson, St George's Hospital, London, and Dr P. C. Mitchell, Carlisle, for supplying isolates. We also thank Dr Elizabeth Asheshov at the Public Health Laboratory, Staphylococcus Reference Laboratory, Colindale, for phage typing the isolates and Dr Heather Dick at the Royal Infirmary, Glasgow, for help in preparing the manuscript.

\section{REFERENCES}

BERNHEIMER, A. W.

Dorfmann, A.

ELEK, S. D.

EleK, S. D., AND Levy, E.

Gillespie, E." H.

Gladstone, G. P.

HALLANDER, H. O.

Holzel, A., AND JACOBS, S. I.

JEFFERSON, J.

LOMINSKI, I., AND ARBUThNoTt, J. P.

Lowney, E. D., Baublis, J. V., KreYe,

G. M., Harrell, E. R., AND McKenzie, A. $\mathbf{R}$.

LyelL, A.

Lyell, A., Dick, Heather, and AlexANDER, J. O'D.

PARKER, M. T.

PARKer, M. T., ANd Simmons, L. E. . .

PARKer, M. T., TOMLINSON, A. J. H., AND Williams, R. E. O.

SAgGers, B. A., AND Stewart, G. T.

SAMUELS, M. J. .

SPITTLEHOUSE, K. E.

Tomlinson, A. J. H., And Parker, M. T.

TYSON, R. G., Ushinski, S. C., AND KISILEVSKY, R.

Wiseman, G. H., AND CaIRD, J. D.
1969. In Microbial toxins, ed. by S. J. Ajl, T. C. Montie and S. Kadis, New York, in press.

1955. In Methods in enzymology, ed. by S. P. Colowick and N. O. Kaplan, New York, vol. 1, p. 166.

1959. Staphylococcus pyogenes, Edinburgh.

1950. J. Path. Bact., 62, 541.

1954. Ibid., 68, 31.

1943. Mon. Bull. Min. Hlth, 2, 19.

1966. Postepy Mikrobiol., 5, 145.

1968. Acta path. microbiol. scand., 72, 586.

1966. Schweiz. med. Wschr., 96, 427.

1967. Br. Med.J., 2, 802.

1962. J. Path. Bact., 83, 515.

1967. Archs Derm., 95, 359.

1967. Br. J. Derm., 79, 662.

1969. Lancet, 1, 787.

1958. J. Hyg., Camb., 56, 238.

1959. J. Gen. Microbiol., $21,457$.

1955. J. Hyg., Camb., 53, 458.

1968. J. Bact., 96, 1006.

1967. Br. J. Derm., 79, 672.

1955. Lancet, 2, 378.

1956. Nature, Lond., 177, 895.

1966. Amer. J. Dis. Child., 111, 386.

1968. Proc. Soc. Exp. Biol. Med., 128, 428. 